ISSN: 2224-0616

Int. J . Agril. Res. Innov. \& Tech. 7 (2): 43-48, December, 2017 Available online at http://www.ijarit.webs.com

\title{
CHARACTERIZATION OF THE EXISTING SOIL MANAGEMENT IN RELATION TO SOME SELECTED PHYSICO-CHEMICAL PROPERTIES AT BULEHORAWOREDA, WEST GUJ I ZONE
}

\author{
Kenea Worku1, Abdissa Debela ${ }^{*}$ and Diriba Shanko²
}

Received 11 August 2017, Revised 2 November 2017, Accepted 24 December 2017, Published online 31 December 2017

\begin{abstract}
The study of soil physico-chemical properties were made on the soils of BuleHoraWoreda, WestGuji zone. The objective of the study was to characterize soil physical and chemical properties to assess the fertility status of the soils in the study areas. Soil profile pits at representative sites were described and soil samples were collected from each depth of 0-15 $\mathrm{cm}, 15-30 \mathrm{~cm}$, and 30-60 cm depending on the root depth of the crop. Soil samples were collected from two different study areas for the determination of soil texture, bulk density, porosity, soil $\mathrm{pH}$ and electrical conductivity. The top layer $(0-15 \mathrm{~cm})$ has an average bulk density of $1.10 \mathrm{~g} / \mathrm{cm}^{3}$, whereas the subsurface layer (15-30 and the bottom layer $(30-60 \mathrm{~cm})$ has an average bulk density of $1.16 \mathrm{~g} / \mathrm{cm}^{3}$ and $1.26 \mathrm{~g} / \mathrm{cm}^{3}$, respectively at the GuyyeKebele. The average value of bulk density $1.18 \mathrm{~g} / \mathrm{cm}^{3}, 1.29 \mathrm{~g} / \mathrm{cm}^{3}$ and $1.39 \mathrm{~g} / \mathrm{cm}^{3}$ was recorded on the surface horizon $(0-15 \mathrm{~cm})$, subsurface horizon $(15-30 \mathrm{~cm})$ and the bottom horizon $(30-60$ $\mathrm{cm})$ depth, respectively at BuleHora Farm. Accordingly, the highest $\left(1.39 \mathrm{~g} / \mathrm{cm}^{3}\right)$ and the lowest $\left(1.10 \mathrm{~g} / \mathrm{cm}^{3}\right)$ average bulk density values were recorded for BuleHoraand GuyyeKebele study Farm, respectively. The average highest porosity (58.48\%) value was observed in the surface horizon $(0-15 \mathrm{~cm})$ soil depth and the average lowest porosity value $(52.11 \%)$ was observed in the bottom horizon $(30-60 \mathrm{~cm})$ depth at GuyyeKebele study Farm. The average porosity value of the soils in BuleHora study Farm were recorded 55.27\%, $52.39 \%$ and $47.63 \%$ for the surface horizon $(0-15 \mathrm{~cm}$ ), sub surface horizon ( $15-30 \mathrm{~cm}$ ) and bottom horizon $(30-60 \mathrm{~cm})$ depth , respectively. The soil textural class was changed with depth from sandy clay in surface horizon $(0-15 \mathrm{~cm})$ to clay in both sub surface horizon (15$30 \mathrm{~cm}$ ) and bottom horizon $(30-60 \mathrm{~cm})$ at GuyyeKebele. The $\mathrm{pH}$ value was observed on the soils of the GuyyeKebele study area increased from 6.08 at surface horizon $(0-15 \mathrm{~cm})$ to 6.27 at the sub surface horizon $(15-30 \mathrm{~cm})$ and then slightly decreased to 6.21 at the bottom horizon $(30-60 \mathrm{~cm})$ of the soil depth. Lowest soil $\mathrm{pH}$ value $(5.44)$ was measured in the surface horizon $(0-15 \mathrm{~cm}$ ) and the highest $\mathrm{pH}$ value (6.09) was observed in bottom horizon (30-60 cm) soil depth at BuleHora farm. The electrical conductivity of the saturated soil paste extracts of the study area was low (ranging from 0.0387 to $0.1587 \mathrm{dS} \mathrm{m}^{-1}$ ) throughout the profile showing no significant accumulation of soluble salts to convert the soil to saline soil.
\end{abstract}

Keywords: Soil Physicochemical Properties, Soil Fertility

\footnotetext{
${ }^{1}$ Department of Natural Resource Management, College of Agricultural Sciences (CAS), BuleHoraUniversity (BHU), P.O. Box: 144, BuleHora, Oromia, Ethiopia

${ }^{2}$ Department of Biology, College of Natural and Computational Sciences (CNCS), BuleHoraUniversity (BHU), P.O. Box: 144, BuleHora, Oromia, Ethiopia

*Corresponding author's email: abdib69@ gmail.com (Abdissa Debela)
}

\section{Introduction}

At present, the issue of soil productivity has become a global concern. According to Brady and Weil (2002), the two major interactive worldwide problems are widespread hunger and malnutrition, and the deterioration of quality of the environment resulting from injudicious attempts made to alleviate hunger and malnutrition. The quality, management and conservation of the world's soils are critical elements in the rectification of the sated problems. The evidence is clear that the soils' natural ability to supply sufficient nutrients has decreased with the higher plant productivity levels associated with increased human demand for food. Soil fertility decline has been described as the single most important constraint to food security in Sub-Saharan Africa (SSA). Soil fertility is not just a problem of nutrient deficiency. It is a problem of soil physicochemical and biological degradation. 
Agriculture is the foundation of the economy of Ethiopia. Agriculture is facing major problems in Ethiopia with recurrent droughts and dependency of agriculture on rainfall, lack of adequate water resources, salinity problems, improper land management and lack of adequate information on soil and other land resources for their unsound management practices could be among other major problems responsible for the existing low food crop production in the country. High quality soil may produce better food and fiber, and helps to establish natural ecosystem and enhance air and water quality. In specific study area, the information presently available on soil fertility status is not adequate to meet the requirement of agricultural development programs, and rational fertilizer promotions and recommendations based on actual limiting nutrients for a given crop. The prevailing blanket fertilizer rate recommendation throughout the country justifies the existence of little information on the fertility status of Ethiopia's soils. Periodic assessment of important soil properties and their responses to changes in land management is necessary in order to improve and maintain the fertility and productivity of soils (Wakene and Heluf, 2003).

The results of soil chemical testing are instrumental in determining the relative ability of a particular soil to supply plant nutrients during a particular crop growing season, predict the probability of obtaining a profitable response to fertilizer application, determine the need to adjust soil $\mathrm{pH}$, diagnose problems such as excessive salinity or sodicity/alkalinity, provide a basis for fertilizer recommendations for a given crop, and evaluate the fertility status of soil as the basis for planning a nutrient management program. The knowledge of soil physical and chemical properties plays a vital role in enhancing production and productivity of the agricultural sector on sustainable basis, very little information is available around BuleHoraWoreda District, in West Guji zone. The main objective of this study is to characterizing of the existing soil management in relation to some physico chemical properties at BuleHora area. Therefore, this study was conducted with the following specific objectives:

- To characterize the physical properties the soils

- To characterize the chemical properties

\section{Materals and Methods}

\section{Description of study area}

West Guji is found in southern part of the Oromia Regional State, Ethiopia. The capital town of the zone is BuleHora; which is far away $467 \mathrm{~km}$ from national capital city of Ethiopia (Addis Ababa).
This zone is located lies between latitudes $5^{0} 26^{\prime}$ and $5^{\circ} 52^{\prime}$ North and longitudes $37056^{\prime}$ and $38^{\circ}$ 31' East and an altitude between 1500 and 2400meters above sea level (Guji Zone land and environment protection office, 2017). West Guji zone is divided into three agro ecology zones, namely the high lands (Dega) 34\%, mid-highland (woinaDega) 55\% and lowlands (kola) 11\%. The rainfall pattern is bimodal i.e. have two distinct rain seasons. The data has taken from BuleHora agricultural office indicates that BuleHoraWoreda receives high rainfall between March and May as well as relatively good amount from September to November. The dry season extends from December to February and to some extent from June to July. The highest mean annual average rainfall of the study area was $1250 \mathrm{~mm}$ whereas the lowest mean average was $600 \mathrm{~mm}$ recorded. The lowest mean average temperature was $15^{\circ} \mathrm{C}$ whereas the highest was $22.8^{\circ} \mathrm{C}$ recorded. KuyyeKebeleand BuleHora Farm site, which is the specific site of the present study area of BuleHora District.

\section{Soil sampling and physicochemical analysis}

Soil sampling

Prior to the opening of soil profiles, a field observation and general visual reconnaissance survey of the area was carried out to determine as to which specific areas should be selected as representative sites of the study area on the basis of land use. After selected the sites, the number of sampling points was determined on the basis of the area coverage of each study area. From each sampling site, to make one composite soil sample, 4 subsamples was augured from each of the specific study areas and well mixed in a bucket. Soil samples were taken from each depth of 0 $15 \mathrm{~cm}, 15-30 \mathrm{~cm}$, and $30-60 \mathrm{~cm}$ of the soil profile depending on the root depth of the crop for characterization of their physicochemical properties on the field. About $1 \mathrm{~kg}$ of the mixed sub-samples (composite samples) was properly labeled/tagged, and taken to the laboratory for analysis.

\section{Soil physicochemical analysis}

Soil samples was collected from two different study area for the determination of soil water content, soil texture, bulk density, soil $\mathrm{pH}$ and electrical conductivity (EC). The procedure described by the FAO (1984) was used to determine the particle size distribution by the hydrometer method. The electrical conductivity of the saturated soil paste extracts (ECe) was determined using electric conductivity meter on the saturated soil paste extract, which were extracted by applying suction with the use of vacuum pump (US Salinity Laboratory Staff, 
1954). Gravimetric method was used to determine the soil moisture. After weighing the soil sample it was placed in an oven at $1050 \mathrm{C}$ for 24 hours. After drying, the soils were weighed again. The soil moisture content was calculated as a dry weighed fraction:

\section{Soil moisture content $(\mathrm{g} / \mathrm{g})=$ Wet weight of soil g - Dry weight(g)}

Dry weight of soil (g)

To determine bulk density, soil sample of known volume was taken using a metal cylinder (core sampler) that is driven into the soil at a desired depth (Sahlemedhin and Taye, 2000). Then the sample was dried in an oven to determine the dry weight fraction. Since bulk density varies considerably spatially, the measurements were taken at several locations. The bulk density was calculated as the ratio of dry weight of soil to a known cylinder core sampler volume.

Buikdensity $\left(\frac{g}{\mathrm{~cm} 3}\right)=\frac{\text { Weightofdrysoll }(\mathrm{g})}{\text { Volumeofcore }(\mathrm{cm} 3)}$

Total porosity was estimated from the values of bulk density (BD) and particle density (PD), with the latter assumed to have the generally used average value of $2.65 \mathrm{~g} / \mathrm{cm}^{3}$ as indicated below (Landon, 1991):

\section{Total porosity $(\%)=[1-(B d / P d)] \times 100$}

The quantitative data was analyzed and presented by using pie charts, tables, graphs and percentages. Classification of salt affected soils based on their chemical properties were done (US Salinity Laboratory Staff, 1954; Tekalign, 1991) for purposes of interpreted as per that suggested.

\section{Results and Discussion}

\section{Soil physical and chemical properties at study area}

Soil bulk density at study area

The bulk density in the surface soil were $1.20 \mathrm{~g}$ $\mathrm{cm}^{-3}, 1.06 \mathrm{~g} \mathrm{~cm}^{-3}$ and $1.05 \mathrm{~g} \mathrm{~cm}^{-3}$ at the Site A, Site B and Site C, were recorded in GuyyeKebele Study Farm Site, respectively (Table 1). The result in table 1 indicated that the average bulk density in the Site A, B and C were $1.17 \mathrm{~g} / \mathrm{cm}^{3}, 1.19$ $\mathrm{g} / \mathrm{cm}^{3}$ and $1.17 \mathrm{~g} / \mathrm{cm}^{3}$, respectively at GuyyeKebele Study Farm Site. The bulk density of soil of the area shows variation with depth and the location (Table 1). It varies between 1.05 to $1.31 \mathrm{~g} / \mathrm{cm}^{3}$ in study area and generally the top surface soil has slightly lower bulk density than the sub-surface. The top horizon $(0-15 \mathrm{~cm})$ has an average bulk density of $1.10 \mathrm{~g} / \mathrm{cm}^{3}$, whereas, the sub-surface horizon $(15-30 \mathrm{~cm})$ and bottom horizon $(30-60 \mathrm{~cm})$ has an average bulk density of 1.16 and $1.26 \mathrm{~g} / \mathrm{cm}^{3}$, respectively at the GuyyeKebele Study Farm. The highest bulk density might be due to loss of organic matter content and compaction resulting from continuous cultivation for many years and other soil parameters such as depth of soils.

The result in table 1 indicated that the average bulk density in the Site A,B and C were 1.33 $\mathrm{g} / \mathrm{cm}^{3}, 1.35 \mathrm{~g} / \mathrm{cm}^{3}$ and $1.18 \mathrm{~g} / \mathrm{cm}^{3}$, respectively at BuleHora Study Farm Site. The top horizon ( 0$15 \mathrm{~cm}$ ) has an average bulk density of $1.18 \mathrm{~g} / \mathrm{cm}^{3}$, whereas, the sub-surface $(15-30 \mathrm{~cm})$ and bottom horizon $(30-60 \mathrm{~cm})$ has an average bulk density of 1.29 and $1.39 \mathrm{~g} / \mathrm{cm}^{3}$, respectively at BuleHora Study Farm Site. Bulk density consistently with the depth of the soil profiles.

Table 1. Bulk density $(\mathrm{g} / \mathrm{cm}$ ) of the soils collected from study area.

\begin{tabular}{|c|c|c|c|c|}
\hline \multicolumn{5}{|c|}{ Soil Bulk Density at GuyyeKebele Study Area } \\
\hline Soil depth & Site A & Site B & Site C & Average Value \\
\hline $0-15$ & 1.20 & 1.06 & 1.05 & 1.10 \\
\hline $15-30$ & 1.11 & 1.23 & 1.14 & 1.16 \\
\hline $30-60$ & 1.20 & 1.27 & 1.31 & 1.26 \\
\hline Average & 1.17 & 1.19 & 1.17 & \\
\hline \multicolumn{5}{|c|}{ Soil Bulk Density at BuleHora Farm Site } \\
\hline $0-15$ & 1.29 & 1.14 & 1.12 & 1.18 \\
\hline $15-30$ & 1.35 & 1.34 & 1.18 & 1.29 \\
\hline $30-60$ & 1.35 & 1.57 & 1.24 & 1.39 \\
\hline Average & 1.33 & 1.35 & 1.18 & \\
\hline
\end{tabular}

The highest $\left(1.39 \mathrm{~g} / \mathrm{cm}^{3}\right)$ and the lowest $(1.10$ $\mathrm{g} / \mathrm{cm}^{3}$ ) average bulk density values were recorded for BuleHora and GuyyeKebele Study Farm Site, respectively. According to Landon (1991), for good plant growth, bulk densities should be below $1.4 \mathrm{~g} / \mathrm{cm}^{3}$ and $1.6 \mathrm{~g} / \mathrm{cm}^{3}$ for clay and sandy soils, respectively. Therefore, the bulk density values observed in the soils studied were within the normal range of mineral soils worldwide, which may not too compact to limit root penetration, root growth, air circulation, water movement and availability of less mobile essential elements such as $\mathrm{P}$ and $\mathrm{K}$. Bulk density is one of the major physical parameters used to evaluate the physical fertility status of soils. 
Total porosity

The total porosity of the soils in the study area ranges between 40.64 and $60.62 \%$ at BuleHora and GuyyeKebele Study Farm Site, respectively. The average value porosity of the soils in GuyyeKebele Study Farm Site were 58.48\%, $56.26 \%$ and $52.11 \%$ for the soil depth $0-15,15-30$ and $30-60 \mathrm{~cm}$, respectively whereas the average value of soil porosity in BuleHorastudy Farm Site were $55.27 \%, 52.39 \%$ and $47.63 \%$ for the soil depth $0-15,15-30$ and $30-60 \mathrm{~cm}$, respectively. The total porosity of the studied area showed

Table 2. Total Porosity (\%) of the study area. variability with respect to soil bulk density as showed on the Table 2 . The higher values of total porosity might be corresponded to the higher amount of organic matter contents and lower bulk density values. Accordingly, total porosity increases as the bulk density decreases while it decreases as bulk density increases. Wakene (2001) reported that the lower total porosity in the sub-soil layers were a result of low OM contents and high bulk density that was imposed by the use of heavy machinery for tillage activity.

\begin{tabular}{|c|c|c|c|c|}
\hline \multicolumn{5}{|c|}{ Soil Porosity at GuyyeKebele Study Farm } \\
\hline Soil Depth & Site A & Site B & Site C & Average Value \\
\hline $0-15$ & 54.77 & 60.12 & 60.54 & 58.48 \\
\hline $15-30$ & 58.16 & 53.58 & 57.04 & 56.26 \\
\hline $30-60$ & 53.66 & 52.16 & 50.51 & 52.11 \\
\hline Average & 55.53 & 55.29 & 56.03 & \\
\hline \multicolumn{5}{|c|}{ Soil Porosity at BuleHora Study Farm } \\
\hline $0-15$ & 51.31 & 56.85 & 57.66 & 55.27 \\
\hline $15-30$ & 49.16 & 49.6 & 55.40 & 51.39 \\
\hline $30-60$ & 49.12 & 40.62 & 53.16 & 47.63 \\
\hline Average & 49.86 & 49.03 & 55.41 & \\
\hline
\end{tabular}

Particle size distribution in the study areas

The result in table 3 indicated that in all soil profiles at the BuleHora Farm and GuyyeKebele study area was clay soil in textural class except surface layer at GuyyeKebele study area. In all study sites, the clay fraction dominated the particle size distributions in all soil profile depth except in the surface horizon at GuyyeKebele site.

Table 3. Particle size distribution and textural class of the soils in the study area.

\begin{tabular}{|c|c|c|c|c|}
\hline \multicolumn{5}{|c|}{ Particle Size Distribution in the BuleHora Farm Site } \\
\hline Soil depth (cm) & $\%$ sand & \% clay & $\%$ silt & Textural class \\
\hline $0-15$ & 22.56 & 52.16 & 25.28 & Clay \\
\hline $15-30$ & 26.56 & 50.16 & 23.28 & Clay \\
\hline $30-60$ & 28.58 & 48.16 & 23.28 & Clay \\
\hline \multicolumn{5}{|c|}{ Particle Size Distribution in the GuyyeKebele Study Site } \\
\hline $0-15$ & 46.56 & 40.16 & 13.28 & Sandy clay \\
\hline $15-30$ & 36.56 & 48.16 & 15.28 & Clay \\
\hline $30-60$ & 42.56 & 44.16 & 13.28 & Clay \\
\hline
\end{tabular}

The soil texture class changed with depth from sandy clay in surface horizon $(0-15 \mathrm{~cm})$ to clay in sub-surface $(15-30 \mathrm{~cm})$ and bottom horizon $(30-$ $60 \mathrm{~cm}$ ) at GuyyeKebele Site. In line with the textural class, the clay and silt fraction increased consistently with depth from the surface layer (0$15 \mathrm{~cm})$ to the subsurface depth $(15-30 \mathrm{~cm})$ of the soil profile at GuyyeKebele Site (Table 3). On the contrary, the content of the sandy fraction decreased consistently with soil depth from the surface layer $(0-15 \mathrm{~cm})$ to the sub-surface layer $(15-30 \mathrm{~cm})$. This differentiation in clay content is attributed to the variability in the degree of weathering, erosion and translocation of clay from the surface to subsurface horizons. Similar results were reported by Mitiku (2000). According to Wakene and Heluf (2004), intensive cultivation contributed to the variation of particle size distribution at the surface horizons.

Soil reaction $(\mathrm{pH})$ and electrical conductivity (EC)

The data on the chemical properties of the study field under crop production are presented in Table 4. The $\mathrm{pH}$ of the soil profile opened at the BuleHora farm was 5.44 on the surface soil depth $(0-15 \mathrm{~cm})$ and increased almost consistently with depth 6.09 at the depth of $30-60 \mathrm{~cm}$. The $\mathrm{pH}$ increased consistently with increasing soil depth with a maximum value of 6.09 in the bottom horizon. The $\mathrm{pH}$ value was observed on the soils of the GuyyeKebele study area increased from 6.08 at surface soil layer to 6.27 at the subsurface depth $(15-30 \mathrm{~cm})$ and then slightly 
decreased to 6.21 at the bottom $30-60 \mathrm{~cm}$ layer of the soil profile (Table 4). The highest $\mathrm{pH}$ value (6.27) was recorded in the subsurface horizon at GuyyeKebele study area while the lowest $\mathrm{pH}$ value 5.44 was recorded in the surface horizon at the BuleHora farm. Considering the soil $\mathrm{pH}$, the soils in the present study area represented by GuyyeKebele and BuleHora study area were slightly acidic (6.0 - 6.6) in all soil profile layer as per the classification set by Tekalign (1991). According to the classification ranges suggested by Brady and Weil (2002), the soil reaction based on the $\mathrm{pH}$ values recorded in the soils of all profiles studied qualify for moderately to slightly acidic reaction classes.

Table 4. Soil reaction $(\mathrm{pH})$ and electrical conductivity of the study area.

\begin{tabular}{lllll}
\hline & \multicolumn{2}{l}{ BuleHora Farm Study Site } & \multicolumn{2}{l}{ GuyyeKebele Study Site } \\
\hline Soil depth $(\mathrm{cm})$ & $\mathrm{pH}$ & EC $($ us/ cm) & $\mathrm{pH}$ & EC (us/ cm) \\
\hline $0-15$ & 5.44 & 0.1587 & 6.08 & 0.0651 \\
$15-30$ & 6.05 & 0.0573 & 6.27 & 0.0387 \\
$30-60$ & 6.09 & 0.0438 & 6.21 & 0.0565 \\
\hline
\end{tabular}

In line with the $\mathrm{pH}$ value, the electrical conductivity of the saturation extracts (ECe) also decreased from $0.1587 \mathrm{dS} \mathrm{m}^{-1}$ at the surface layer to $0.0573 \mathrm{dS} \mathrm{m}^{-1}$ at the depth of $15-30 \mathrm{~cm}$ and then slightly decreased to $0.0438 \mathrm{dS} \mathrm{m}^{-1}$ at the bottom 30-60 cm layer of the soil profileat the BuleHora study farm. The ECe of the soil was low (ranging from 0.0387 to $0.0651 \mathrm{dS} \mathrm{m}^{-1}$ ) throughout the profile showing no significant accumulation of soluble salts to convert the soil to saline soil at the GuyyeKebele study farm.The ECe of the study area soil was low (ranging from 0.0387 to $0.1587 \mathrm{dS} \mathrm{m}^{-1}$ ) throughout the profile showing no significant accumulation of soluble salts to convert the soil to saline soil as per the criteria developed by the US Salinity laboratory Staff (1954).

\section{Conclusions}

Ethiopia is endowed with potentially rich natural resources, of which land is the principal one. However, its productivity is continuously declining due to continuous cultivation, intensive grazing and traditional farming practices without the use of organic and/or inadequate inorganic fertilizer inputs. These problems need to be alleviated through prevention of further degradation of the land, rehabilitation of the degraded ones and preparation of a rational land use planning for agriculture. In addition, sufficient knowledge on the properties of soils is prerequisite for designing appropriate management strategies and thereby solving. Laboratory analyses were carried out to study the physicochemical properties of the soils at BuleHoraWoreda.

Soil samples were collected from two different study areas for the determination of soil texture, bulk density, porosity, soil $\mathrm{pH}$ and electrical conductivity (EC).The top layer $(0-15 \mathrm{~cm})$ has an average bulk density of $1.10 \mathrm{~g} / \mathrm{cm}^{3}$, whereas the subsurface layer (15-30 and the bottom layer (30$60 \mathrm{~cm}$ ) has an average bulk density of 1.16 and $1.26 \mathrm{~g} / \mathrm{cm}^{3}$, respectively at the GuyyeKebele Study
Farm. The average value of bulk density 1.18 $\mathrm{g} / \mathrm{cm}^{3}, 1.29 \mathrm{~g} / \mathrm{cm}^{3}$ and $1.39 \mathrm{~g} / \mathrm{cm}^{3}$ was recorded on the surface horizon $(0-15 \mathrm{~cm})$, sub-surface horizon (15 - $30 \mathrm{~cm}$ ) and the bottom horizon (30 - $60 \mathrm{~cm})$, respectively at BuleHora Farm Site . The average highest porosity (58.48\%) value was observed in the surface horizon $(0-15 \mathrm{~cm})$ and the average lowest porosity value (52.11\%) was observed in the bottom horizon $(30-60 \mathrm{~cm})$ at GuyyeKebele Study Farm Site. The average porosity value of the soils in BuleHora Study Farm Site were recorded $55.27 \%, 52.39 \%$ and $47.63 \%$ for the surface horizon $(0-15 \mathrm{~cm})$, subsurface horizon $(15-30 \mathrm{~cm})$ and bottom horizon $(30-60 \mathrm{~cm})$, respectively. The soil textural class was changed with depth from sandy clay in surface horizon $(0-15 \mathrm{~cm})$ to clay in both sub surface horizon $(15-30 \mathrm{~cm})$ and bottom horizon (30-60 cm) at GuyyeKebele Study Site. The pH value was observed on the soils of the GuyyeKebele study area increased from 6.08 at surface horizon $(0-15 \mathrm{~cm})$ to 6.27 at the sub surface horizon $(15-30 \mathrm{~cm})$ and then slightly decreased to 6.21 at the bottom horizon (30-60 $\mathrm{cm})$ of the soil profile.

\section{References}

Brady, N.C. and Weil, R.R. 2002. The nature and properties of soils. $13^{\text {th }}$ ed., Prentice-Hall Inc., New J ersey, USA. 960 p.

FAO. 1984. Physical and chemical methods of soils and plant analysis, FAO soils Bulletin No. 10, Food and Agricultural Organization of the United Nations, Rome.

Landon, J.R. 1991. Booker tropical soil manual: A handbook for soil survey and agricultural land evaluation in the tropics and subtropics. Longman Scientific and Technical, Essex, New York. $474 \mathrm{p}$.

Mitiku, B. 2000. Study on some important physiochemical characteristics of Gnaroplantation and natural junipers forest soils, Borena, Southern Ethiopia. M.Sc. Thesis. School of Graduate Studies, Alemaya University, Ethiopia. 79 p. 
Sahlemedhin, S. and Taye, B. 2000. Procedure for soil and plant analysis. National Soil Research Centre, Ethiopian Agricultural Research Organization, Addis Ababa, Ethiopia. $110 \mathrm{p}$.

Tekalign, T. 1991. Soil, plant, water, fertilizer, animal manure and compost analysis. Working Documnt NO 13. International Livestock Research Center for Africa (ILCA), Addis Ababa.

US Salinity Laboratory Staff, 1954. Diagnosis and improvement of saline and alkali soils. USDA Agriculture Handbook. No. 60. 160 p.

Wakene Negassa, 2001. Assessment of important physic-chemical properties of Dystric Udalf (Dystric Nitosols) under different management systems in Bako area, Western Ethiopia. M.Sc. Thesis. School of Graduate Studies, Alemaya University, Ethiopia. 93 p.

Wakene, N. and Heluf, G. 2003. Influence of land management on morphological, physical and chemical properties of some soils of Bako, western Ethiopia, Agropedol. 13 (2): 1-9.

Wakene, N. and Heluf, G. 2004. The impact of different land use systems onsoil quality of western Ethiopia Alfisols. pp. 1-7. International Research on Food Security: Natural Resource Management and Rural Poverty Reduction through Research for Development and Transformation. Deutcher Tropentage-Berlin 5-7 October 2004. 